\title{
Intrathecal Baclofen Preserves Walking Ability in Multiple Sclerosis Related Spasticity: A Case Report
}

\author{
Simeoni $\mathbf{S}^{1 *}$, Sparkes $\mathbf{S}^{1}$, Keenan $\mathbf{E}^{1}$, Buchanan $\mathbf{K}^{1}$, \\ Lee $\mathrm{H}^{1}$, Padilla $\mathrm{C}^{1}$, Stevenson $\mathrm{VL}^{1,2}$ and Farrell $\mathrm{R}^{1,2}$ \\ ${ }^{1}$ National Hospital for Neurology and Neurosurgery, \\ UCLH NHS Foundation Trust, London, UK \\ ${ }^{2}$ University College London, Institute of Neurology, \\ London, UK \\ *Corresponding author: Simeoni S, The National \\ Hospital for Neurology and Neurosurgery, WC1N 3BG, \\ London, UK; E-mail: simeoni_sara85@yahoo.it
}

Received: September 25, 2017; Accepted: October 17, 2017; Published: October 24, 2017

\section{Keywords}

Intrathecal Baclofen; Multiple Sclerosis; Spasticity; Walking

\section{Introduction}

Spasticity was defined by Lance in 1980 as a motor disorder characterized by a velocity dependent increase in the tonic stretch reflex (muscle tone) with exaggerated tendon jerks, resulting from hyperexcitability of the stretch reflex, as one component of the upper motor neurone syndrome [1]. It affects about $84 \%$ of patients with multiple sclerosis (MS) with various degrees of severity and may have a detrimental effect on daily activities and quality of life [2,3]. Studies have demonstrated that early and effective management of spasticity could improve patients's quality of life and lead to significant cost savings [4]. There is limited evidence of the effectiveness of oral antispasticity medications, which may be associated with intolerable side effects. Studies have demonstrated that intrathecal baclofen (ITB) therapy is an effective treatment for severe spasticity of cerebral and spinal origin [5], but there are still barriers to its use due to misperception of its risk, cost and failure of physicians to recognise the impact of spasticity on patients' quality of life [6]. We report the case of a wheelchair-dependent patient with MS who experienced multiple benefits including the ability to access her underlying muscle strength and walk again following ITB system implantation.

\section{Case Presentation}

We report the case of a 42 year old lady with spastic paraparesis secondary to relapsing remitting multiple sclerosis diagnosed 5 years previously. At the time of presentation she was being treated with Alemtuzumab and was able to complete a 25 foot walk test in 27 steps at a speed of 0.78 feet per second ( $\mathrm{ft} / \mathrm{s}$ ) with a frame having recently commenced treatment with PR-Fampridine. She was affected by severe, frequent and painful flexor spasms of her right lower limb and mild to moderate extensor spasms of her left lower limb (Modified Penn Spasm Scale: frequency 4-3, severity 3-2 respectively). The spasms were both spontaneous and triggered by touch and movement. Tone was significantly increased in the right knee flexors (Ashworth grade 3 ) and extensors (Ashworth grade 2) and slightly increased in the left knee extensors and bilateral ankle plantarflexors (Ashworth grade 1). The MRC muscle score was between grade 3 and 4 throughout the left lower limb and between grade 2 and 3 throughout the right lower limb. Spasticity was initially managed with high-dose oral medications (Baclofen 120mg daily, gabapentin 3600mg daily) but progressively worsened with a negative impact on her mobility such that she had not been able to walk functionally over the previous six months. She had commenced Nabiximols (THC:CBD Sativex ${ }^{\circ}$ ) and escalated the dose to 10 sprays per day. Despite some benefit with improved pain and reduced severity of spasm she continued to have flexor spasm on the right triggering severe back pain, hyperaesthesia in the limb and continued loss of range at the knee. An MRI spine was consistent with demyelination and no other cause for the back pain identified. ITB therapy was discussed with the patient in the context of a multidisciplinary assessment. The agreed goals were to decrease the frequency, amplitude, and intensity of spasms, to reduce pain, to improve lower limb comfort and sleep, to improve the safety of her transfers and explore the possibility of returning to walk through allowing her to access her underlying muscle strength. The patient underwent a successful ITB trial $(50 \mathrm{mcg})$ and was subsequently implanted with an ITB pump (Medtronic SynchroMed II) without complications; the starting dose was $100.1 \mathrm{mcg}$ daily. Oral treatments (baclofen, nabiximols and gabapentin) were gradually discontinued.

Following ITB pump implantation, spasticity and spasms significantly improved and the patient received regular physiotherapy as a day patient in a rehabilitation unit. The ITB dose was optimised in order to achieve a balance between spasticity relief and satisfactory functional status ( $93 \mathrm{mcg}$ daily). At one-month follow-up assessment, the Ashworth was graded as 0 throughout her lower limbs except for ankle plantarflexors and knee flexors bilaterally (Ashworth grade 1) and only brief, non-painful and small amplitude spasms of her right lower limb a triggered (Modified Penn Spasm Scale: frequency 0 (left lower limb), (right lower limb), severity 0 (left lower limb)-1 (right lower limb)). Her back and lower limb pain and hyperaesthesia completely resolved (VAS 0/10) and her sleep improved. At onemonth follow up the patient was able to walk over $10 \mathrm{~m}$ with a wheeled zimmer frame. Subsequently she continued to work on her walking with her community physiotherapist and she was provided with bilateral functional electrical stimulation (FES). At three-month follow up she was able to walk approximately $20 \mathrm{~m}$ with a wheeled zimmer frame and bilateral FES before needing to stop to rest and she was able to perform independent standing transfers with the frame; she completed a 25 foot walk test at a speed of $0.67 \mathrm{ft} / \mathrm{s}$. At sevenmonth follow up she completed a 25 foot walk test in 24 steps at a speed of $0.58 \mathrm{ft} / \mathrm{s}$.

\section{Discussion}

This case demontrates that ITB therapy may not only improve spasticity but also gait performance, pain management and sleep in patients with MS. Studies have demonstrated that ITB therapy is
Phys Med Rehabil Int - Volume 4 Issue 4 - 2017

ISSN : 2471-0377 | www.austinpublishing group.com

Simeoni et al. (C) All rights are reserved
Citation: Simeoni S, Sparkes S, Keenan E, Buchanan K, Lee H, Padilla C, et al. Intrathecal Baclofen Preserves Walking Ability in Multiple Sclerosis Related Spasticity: A Case Report. Phys Med Rehabil Int. 2017; 4(4): 1127. 
safe and effective in ambulatory MS patients with moderate to severe spasticity and may contribute to improvement and preservation of long-term ambulation $[7,8]$. To our knowledge, this is the first reported case of a previously non-ambulatory patient with MS who could walk again after ITB system implantation. Ordia et al $[8,9]$ reported in 2002 three cases of previously non-ambulatory patients who could ambulate again following ITB system implantation $[8,9]$ who were affected by traumatic brain injury, cervical spondylotic myelopathy and subluxation of the cervical spine and spinal cord compression due to rheumatoid arthritis, respectively.

The preservation and potential improvement of walking performance appear to be related to the underlying lower limb muscle strength, therefore selection of candidates for ITB should be very careful $[5,7]$. The case reported suggests that the reduction in spasticity allows for intensive post-operative rehabilitation in patients with good muscle strength, contributing to the improvement of ambulatory function [7,9]. As previously reported [7], in ambulatory patients ITB dose titration and optimisation may take some weeks because the aim would be to achieve a satisfactory balance between spasticity relief and functional ambulation.

This case suggests that ITB therapy may exert beneficial effects on aspects that have a significant impact on quality of life of MS patients, including pain and sleep. Patients with MS have a high prevalence of pain, which appears to be neuropathic, somatic and visceral in nature [10]. Recent studies have found that ITB therapy may improve pain relief in MS patients [7,8]. ITB may exert analgesic effects through different mechanisms; in fact, it may act at both spinal and supraspinal levels and appears to be able to reduce not only muscle spasms-induced pain but also neuropathic pain and sympathetically mediated pain [11]. The intrinsic antinociceptive effects of baclofen have been demonstrated in experimental animal models at doses that produce no motor impairment [11]. With regard to sleep, compared with oral baclofen, ITB therapy has been demonstrated to improve sleep time and efficiency without affecting respiratory function [12].

\section{Conclusion}

ITB therapy should be regarded as an effective treatment option in the management of severe spasticity in patients with MS at all disability levels. ITB may contribute to the maintenance and improvement of gait performance in patients with sufficient lower limb muscle strength and may exert multiple beneficial effects, improving symptomatic treatment and overall quality of life in patients with MS, particularly when combined with other rehabilitation strategies.

\section{References}

1. Lance JW. Symposium synopsis. In: Feldman RG, Young RR, Koella WP (eds) Spasticity, disordered motor control. Chicago: Year Book Medical Publishers. 1980; 485-494.

2. Rizzo MA, Hadjimichael OC, Preiningerova J, Vollmer TL. Prevalence and treatment of spasticity reported by multiple sclerosis patients. Mult Scler. 2004; 10: 589-595.

3. Kister I, Chamot E, Salter AR, Cutter GR, Bacon TE, Herbert J. Disability in multiple sclerosis: A reference for patients and clinicians. Neurology. 2013; 80: 1018-1024.

4. Stevenson VL, Gras A, Bárdos JI, Broughton J. The high cost of spasticity in multiple sclerosis to individuals and society. Mult Scler. 2015; 21: 1583-1592.

5. Stevenson VL, Jarrett L. Spasticity Management: A Practical Multidisciplinary Guide. Second edition. 2016.

6. Erwin A, Gudesblatt M, Bethoux F, Bennett SE, Koelbel S, Plunkett R, et al. Intrathecal baclofen in multiple sclerosis: too little, too late? Mult Scler. 2011; 17: 623-629.

7. Sadiq SA and Wang GC. Long-term intrathecal baclofen therapy in ambulatory patients with spasticity. J Neurol. 2006; 253: 563-569.

8. Ordia JI, Fischer E, Adamski E, Chagnon KG, Spatz EL. Continuous intrathecal baclofen infusion by a programmable pump in 131 consecutive patients with severe spasticity of spinal origin. Neuromodulation. 2002; 5: 1624.

9. Ordia JI, Fischer E, Adamski E, Spatz EL. Continuous intrathecal baclofen infusion delivered by a programmable pump for the treatment of severe spasticity following traumatic brain injury. Neuromodulation. 2002; 5: 103107.

10. Solaro C, Brichetto G, Amato MP, Cocco E, Colombo B, D'Aleo G, et al. The prevalence of pain in multiple sclerosis: a multicenter cross-sectional study. Neurology. 2004; 63: 919-921.

11. Slonimski M, Abram SE, Zuniga RE. Intrathecal baclofen in pain management. Regional Anesthesia and Pain Medicine. 2004; 29: 269-276.

12. Bensmail D, QueraSalva MA, Roche N, Benyahia S, Bohic M, Denys P, et al Effect of intrathecal baclofen on sleep and respiratory function in patients with spasticity. Neurology. 2006; 67: 1432-1436.
Phys Med Rehabil Int - Volume 4 Issue 4 - 2017 ISSN : 2471-0377 | www.austinpublishing group.com Simeoni et al. (C) All rights are reserved
Citation: Simeoni S, Sparkes S, Keenan E, Buchanan K, Lee H, Padilla C, et al. Intrathecal Baclofen Preserves Walking Ability in Multiple Sclerosis Related Spasticity: A Case Report. Phys Med Rehabil Int. 2017; 4(4): 1127. 